\title{
ОКИСЛИТЕЛЬНАЯ ДЕСТРУКЦИЯ ЛИГНИНСОДЕРЖАЩИХ ПРИМЕСЕЙ ЛЬНА
}

\author{
Н. С. Дымникова, Е.В. Ерохина
}

\begin{abstract}
НАТАЛЬЯ СЕРГЕЕВНА ДЫМНИКОВА - кандидат технических наук, научный сотрудник лаборатории «Химия и технология модифицированных волокнистых материалов» ИХР PAH. E-mail: nsd@isc-ras.ru.
\end{abstract}

ЕКАТЕРИНА ВЯЧЕСЛАВОВНА ЕРОХИНА - кандидат химических наук, младиий научный сотрудник лаборатории «Химия $и$ технология модифицированных волокнистых материалов» ИХР РАН. E-mail: erochina2007@yandex.ru.

153045, г. Иваново ул. Академическая, д. 1. Институт химии растворов им. Г.А. Крестова Российской академии наук.

Комплексными исследованиями нерастворившегося осадка лигнина Класона изучено образование его водорастворимых продуктов, а методом ИК-спектроскопии - состояние лигнина Класона, видоизмененного обработкой щелочным, пероксидными растворами и последующей окислительной варкой. Анализ спектрофотометрических исследований показал, что их максимальные изменения по сравнению с исходными происходят после активачии лигнина пероксидом водорода в щелочной и кислой средах. Менее значительный уровень изменений состояния лигнина в щелочной среде обусловлен конденсаиией образуюшихся низкомолекулярных продуктов.

Ключевые слова: лигнин Класона, лен, растворимость, гидролитическая и окислительная деструкция, ИК-спектроскопия, конденсация.

\section{OXIDATIVE DEGRADATION OF LIGNIN-CONTAINING FLAX IMPURITIES}

\author{
N.S. Dymnikova, E. V. Erohina
}

G.A. Krestov Institute of Solution Chemistry of the Russian academy of Sciences, Akademicheskaya St., 1 Ivanovo, 153045, Russia.

Complex studies of the insoluble precipitate of lignin Klasson studied the formation of its water-soluble products, and by IR spectroscopy - the state of lignin Klasson, modified by treatment with alkaline, peroxide solutions and subsequent oxidative cooking. Analysis of spectrophotometric studies has shown that their maximum changes in comparison with the initial ones occur after activation of lignin with hydrogen peroxide in alkaline and acidic environments. A less significant level of changes in the state of lignin in an alkaline medium is due to condensation of the resulting low-molecular products.

Keywords: Clason lignin, flax, solubility, hydrolytic and oxidative degradation, IR and UV spectroscopy, condensation, pyrocatechin, vanillin. 


\section{Введение}

Подготовка льноволокон для новых видов продукции медицинского, технического и специального назначения требует обеспечения им новых свойств, например, высокой степени извлечения примесей, (содержание альфа-целлюлозы 96,0-99,0 \%), высоких показателей поглотительной способности (не менее 19 г/г волокна), капиллярности (не менее 75 мм), белизны (не менее 72 \%) [1]. Поэтому проблема разработки приемов глубокой очистки льноволокон, сообщения им высоких сорбционных показателей и белизны является своевременной и актуальной.

Вследствие специфичности структуры волокон льна, способности распадаться на мелкие комплексы и элементарные волокна, процессы их облагораживания проводят в мягких условиях, что затрудняет извлечение трудноудаляемых примесей, прежде всего, лигнинсодержащих. Одной из наиболее сложных проблем является делигнификация льна без использования экологически опасных хлорсодержащих реагентов, т.к. применяемый в этих случаях пероксид водорода уступает последним в активности.

Лигнин в своем составе имеет хромофорные группы, придающие ему цвет, который усиливается после отварки волокна в щелочной среде. Окраска связана с наличием в структуре лигнина фенольных или энольных гидроксилов. Кроме того, во время щелочных обработок одновременно с процессом гидролитической деструкции [2] идет конденсация лигнинов и образование значительного количества хромофорных структур, придающих целлюлозному материалу темный цвет [3].

Таким образом, не только достаточно сложно извлечь примеси из срединных пластин и элементарных волокон, но и достаточно сложно разрушить их хромофорные системы, обеспечить требуемые высокие показатели белизны.

Цель данной работы - выбор оптимальных условий активации лигнина для его деструкции и последующего извлечения из лубяных волокон на стадии химической модификации волокна.

\section{Экспериментальная часть}

Лигнин Класона выделяли из сурового льняного волокна согласно методике [4].

При исследовании деструкционных превращений лигнина Класона обработку его щелочными, щелочно-окислительными и щелочно-восстановительными растворами (составы и концентрации растворов приведены в табл. 1) проводили в металлических стаканчиках с плотно завинчивающимися крышками при температуре $100{ }^{\circ} \mathrm{C}$ в течение 110 мин при жидкостном модуле 10 и массе образца 1 г, взвешенного с точностью до 0,01 \%. После окончания процесса гидролиза обработанный лигнин тщательно промывали, сушили до постоянной массы при температуре $105^{\circ} \mathrm{C}$ и взвешивали. По разнице массы образца до и после обработки судили о степени растворения лигнинсодержащих примесей.

ИК-спектрофотометрические измерения проводили на Фурье-спектрофотометре VERTEX 80v в области частот 400-4000 $\mathrm{cm}^{-1}$. Образцы лигнина для снятия ИК-спектров, содержащие 1 мг анализируемого вещества в 100 мг КВr (марки осч.), прессовали в таблетки толщиной 0,1-0,3 мм под давле-

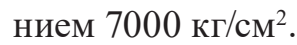

\section{Обсуждение результатов}

Лигнин - полифункциональный полимер, состоящий из целого набора разнообразных функциональных групп: метоксильных $\left(-\mathrm{OCH}_{3}\right)-4,27-$ 4,47 \%, гидроксильных (-OH) фенольных и алифатических - 6,5-8,78 \%, карбонильных $(\mathrm{C}=\mathrm{O})-3,31-$ 7,25 \%, карбоксильных - 2,49-6,5 \% (-СООН) [5-7]. Макромолекулы лигнина состоят из фенилпропановых единиц (I), гваяцильных (II) и сирингильных (III) фрагментов [8, 9], см. рис. 1. Сложное химическое строение лигнолитического комплекса, многообразие его структурных элементов и изменение их в процессе обработок затрудняют проведение глубокой делигнификации целлюлозных материалов.

Как известно, химические превращения лигнина протекают в двух противоположных направлениях:

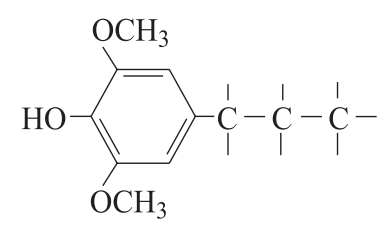

III

Рис. 1. Фрагменты, составляющие макромолекулу лигнина 
- гидролитические и окислительные процессы, сопровождающиеся деструкцией лигнина, образованием растворимых продуктов, разрушением его хромофорных систем;

- конденсационные процессы, приводящие к полимеризации низкомолекулярных фрагментов, укрупнению и упрочнению структур, повышению их цветности.

В процессе делигнификации древесины превалирование первого направления достигается созданием жестких условий обработки (повышением концентрации реагентов, температуры и т.д.), которые являются неприемлемыми для лубяных волокон. Поэтому, в мягких условиях облагораживания льна повышение степени извлечения лигнина может обеспечиваться путем сведения к минимуму его конденсационных превращений. Кроме того, извлечение лигнина из целлюлозных материалов проводится поэтапно, и многостадийный процесс его окислительной деструкции принято рассматривать как единый комплекс окислительно-восстановительных превращений, каждая из стадий которого активирует лигнин, создавая активные центры для реагентов различной природы [1]. Выявление условий предварительной активации лигнина позволит обеспечить более эффективную делигнификацию волокон льна в пероксидсодержащих растворах.

В таблице 1 представлены данные, характеризующие образование водорастворимых продуктов при окислительной варке (щелочным раствором $\mathrm{H}_{2} \mathrm{O}_{2}$ ) лигнина Класона, видоизмененного предшествующим воздействием кислоты, щелочи, пероксида водорода и восстановителя.

Данные таблицы 1 показывают, что на стадии предварительной обработки образование низкомолекулярных продуктов гидролиза и окислитель- ной деструкции более активно проходит в щелочной среде. Даже в сравнительно мягких условиях щелочной обработки растворимость лигнина Класона, выделенного из льняного волокна, составляет $19,8-21,8 \%$, что в 3-3,5 раза выше, чем в кислой среде.

Различия в изменении состояния лигнина обуславливают и различный уровень деградации его на последующей стадии обработки раствором пероксида водорода. Так, суммарная растворимость в процессах активирования лигнина в щелочной среде и последующей обработки раствором пероксида водорода составила 40,4-45,9 \%. После активации в кислой среде растворимость на второй стадии составляет лишь 14,7 \%.

Выявить глубину различий в химических трансформациях лигнина Класона после двухстадийных обработок активаторами и пероксидсодержащим раствором позволяют результаты ИК-спектроскопических исследований его нерастворившейся части (остаточного лигнина). Спектральные кривые исходного (1) и обработанного в различных условиях лигнинов (2-4) приведены на рис. 2.

Огромное число работ посвящено изучению препаратов лигнина, выделенного из древесины, в отличие от лигнина льна. Поэтому при обсуждении полученных нами данных мы основывались на общих закономерностях, присущих лигнину лиственных и хвойных пород древесины.

Полученный нами спектр исходного лигнина Класона аналогичен спектру лигнина из древесины. Положение максимумов основных полос поглощения (а их в лигнине около $20[6,7])$ для всех лигнинов в основном одинаково. Различия выявляются только в интенсивности и, соответственно, в соотношении полос поглощения.

Таблииа 1

Влияние предварительных обработок на степень растворения лигнина Класона при окислительной варке (щелочным раствором $\mathrm{H}_{2} \mathrm{O}_{2}{ }^{*}$ )

\begin{tabular}{|c|c|c|c|c|c|}
\hline \multicolumn{3}{|c|}{$\begin{array}{c}\text { Условия } \\
\text { предварительной обработки }\end{array}$} & \multicolumn{3}{|c|}{$\begin{array}{c}\text { Степень растворения лигнина Класона, (\%) } \\
\text { после обработки: }\end{array}$} \\
\hline $\begin{array}{c}\text { активаторы } \\
\text { процессов, C·10², M } \\
\text { (среда) }\end{array}$ & $\begin{array}{c}\text { общая } \\
\text { щелочность } \\
\text { С·10², M }\end{array}$ & $\begin{array}{c}\text { общая } \\
\text { кислотность } \\
\text { С·10 } 10^{2}, M\end{array}$ & $\begin{array}{l}\text { предвари- } \\
\text { тельной }\end{array}$ & $\begin{array}{c}\text { щелочным } \\
\text { раствором } \\
\mathrm{H}_{2} \mathrm{O}_{2}^{*}\end{array}$ & суммарная \\
\hline- & 25 & & 19,8 & 20,6 & 40,4 \\
\hline $\mathrm{Na}_{2} \mathrm{SO}_{3}-4,0$ (щелочная) & 25 & & 21,8 & 24,1 & 45,9 \\
\hline $\mathrm{H}_{2} \mathrm{O}_{2}^{*}-12,0$ (щелочная) & 25 & & 20,7 & 23,9 & 44,6 \\
\hline $\mathrm{H}_{2} \mathrm{O}_{2}$ (кислая) & & 1,5 & 6,1 & 14,7 & 20,8 \\
\hline
\end{tabular}

Концентрация пероксида водорода в растворах составляла $12 \cdot 10^{-2} \mathrm{M}$.

* растворы, содержащие стабилизаторы разложения пероксида водорода. 


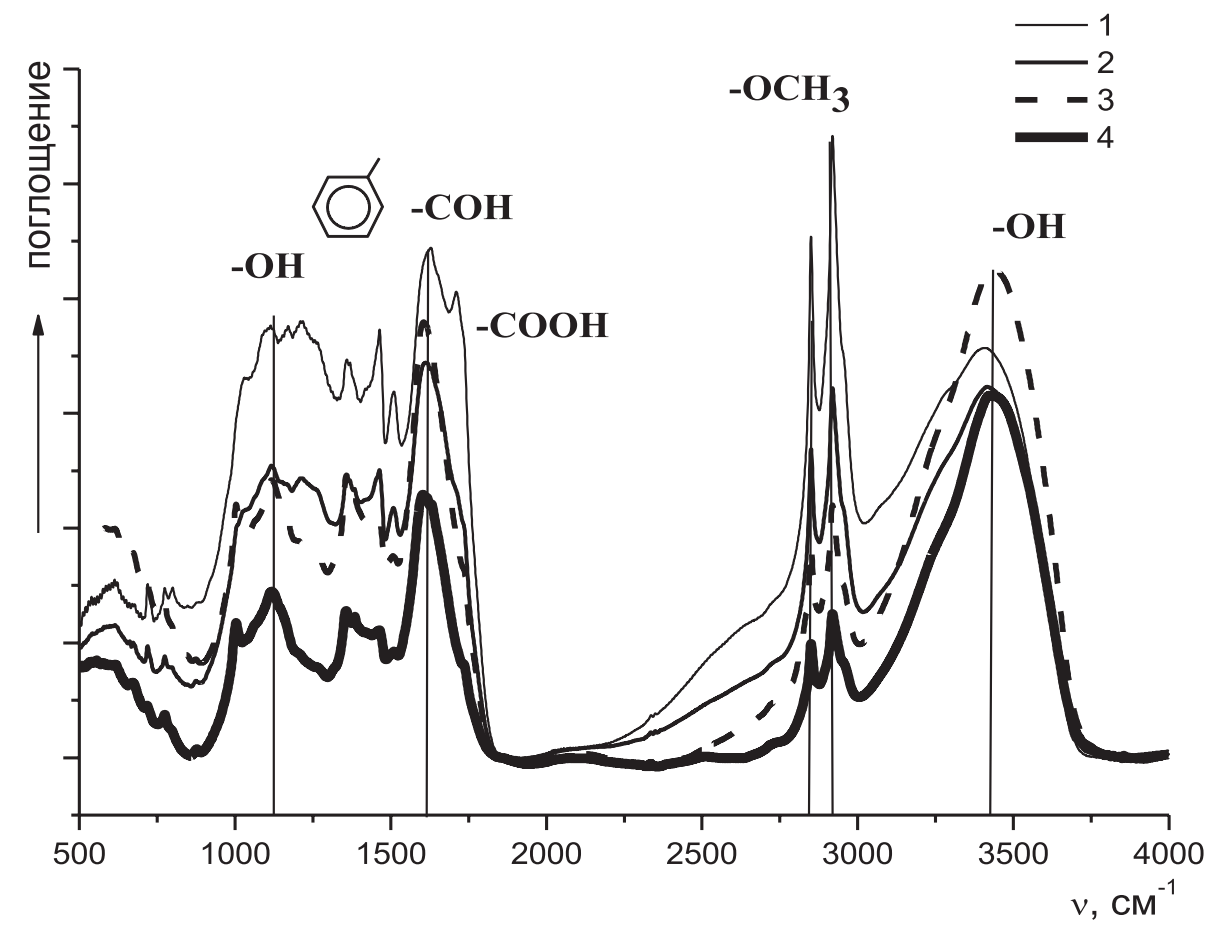

Рис. 2. ИК-спектры лигнина Класона исходного (1) и остаточного (2-4) после обработки его: $2-\mathrm{H}_{2} \mathrm{O}_{2}$ в кислой среде, 3 - $\mathrm{Na}_{2} \mathrm{SO}_{3}$ в щелочной среде, 4- $\mathrm{H}_{2} \mathrm{O}_{2}$ в щелочной среде

Как и в спектре диоксанлигнина хвойных и лиственных пород [6, 10-14], для лигнина Класона, выделенного из льняного волокна, наблюдаются широкая полоса поглощения в области 3460 $3400 \mathrm{~cm}^{-1}$, которая характеризует валентные колебания ОН групп, включенных в межмолекулярные водородные связи различной прочности. Целый ряд полос в области 1508-1117 см ${ }^{-1}$ (скелетные колебания ароматических и алифатических структур) и 1000-700 см ${ }^{-1}$ (внеплоскостные деформационные колебания незамещенного водородного атома ароматического кольца), ответственных за состояние ароматической части. Наблюдаются также полосы поглощения в области 2940-2800 cm${ }^{-1}$, характеризующие симметричные и асимметричные валентные колебания связи С-Н в метильных и метиленовых группах, а в области 1707 и $1604 \mathrm{~cm}^{-1}-$ две отчетливые полосы, связанные с валентными колебаниями карбоксильных и карбонильных групп.

Среди исследователей нет единого мнения, какие группировки ответственны за состояние лигнина в процессах активирующих обработок. Так, согласно данным в работе [6], наиболее важными функциональными группами в лигнине, с точки зрения реакционной способности, являются фенольные гидроксилы, потому что они являются единственным типом функциональных групп, придающих лигнину растворимость в воде при обра- ботке волокна. С точки зрения перспективы отбелки целлюлозы выгодно, чтобы остаточный лигнин имел высокое содержание свободных фенольных гидроксилов, потому что с окислителями, такими как кислород, преимущественно реагируют структуры, имеющие эти функциональные группы.

В работах $[5,15]$ показано, что наиболее характерными группами в лигнине являются метоксильные группы, содержание которых служит критерием химических изменений, происходящих при активации лигнина, что является своего рода характеристикой стабильности бензольного цикла. Однако большинство исследователей исследуют изменения после активации лигнина всего набора основных функциональных групп.

Согласно представленным спектрам на рис. 2, условия обработки существенным образом меняют состояние остаточного лигнина. Так, в области колебаний гидроксильных групп (3460-3400) $\mathrm{cm}^{-1}$ оптическая плотность при $3424 \mathrm{~cm}^{-1}$ после щелочно-восстановительной обработки и активации пероксидом водорода в кислой среде (кривые 2 и 4) снижается, что свидетельствует об увеличении содержания гидроксильных групп, вовлеченных в водородные связи. Это, по-видимому, является следствием протекания конденсационных превращений. Напротив, при активации лигнина сульфитом натрия в щелочной среде (кривая 3) наблюдается увеличение оптической плотности с 33 до 43. 
В этих условиях обработки нуклеофильная атака приводит к расщеплению алкиларильных простых эфирных связей с образованием свободных фенольных гидроксилов $[15,16]$.

В области валентных колебаний C-H связей наблюдается гипохромный эффект для характеристических полос 2918 и $2850 \mathrm{~cm}^{-1}$, свидетельствующий об уменьшении содержания метоксильных групп (-ОCH $)_{3}$ в препаратах окисленного лигнина. Согласно представленным спектрам, максимальные изменения значений оптической плотности в этой области наблюдаются при активации $\mathrm{H}_{2} \mathrm{O}_{2}$ в щелочной среде (кривая 4). Незначительное содержание $\mathrm{OCH}_{3}$-групп в остаточном лигнине свидетельствует о преимущественном протекании реакций окислительного распада ароматического ядра при обработке пероксидом водорода в щелочной среде.

Существенные изменения наблюдаются в области валентных колебаний карбоксильных и карбонильных групп (1720-1600 cm $\left.\mathrm{cm}^{-1}\right)$. Изменение контура полос в данной области выражается в том, что в расщепленной для исходного лигнина полосе (кривая 1) исчезает максимум поглощения карбоксильных групп при 1720 и становится более выраженной полоса карбонильных групп (1604 см-1) для активированных лигнинов (кривые 2-4) . Карбонильные группы являются характерными функциональными группами окисленных лигнинов, т.к. они высокополярны и образуются на первых стадиях обработки в реакционноспособном возбужденном состоянии при распаде диоксетантов, являющихся промежуточными соединениями при деструкции ароматических ядер и боковой цепи ФПЕ [17]. Резкое снижение содержания CO-групп при активации $\mathrm{H}_{2} \mathrm{O}_{2}$ в щелочной среде (кривая 4) обусловлено развитием реакции окисления карбоксильных групп боковой цепи, а также элиминированием (отщеплением) СО-содержащих фрагментов боковой цепи $[6,7,15]$.

Значительные качественные изменения наблюдаются в области колебаний ароматических структур, а именно различие соотношений полос поглощения, ответственных за колебания гваяцильных (1100-1210 $\left.\mathrm{cm}^{-1}\right)$ и сирингильных структур (1358-1464 см$\left.{ }^{-1}\right)$. В работах Файкса [18] доказано, что интенсивность полосы поглощения при 1350 уменьшается с уменьшением содержания сирингильных структур в лигнине. Разное соотношение интенсивностей полос относительно друг друга в данном наборе может свидетельствовать о том, что процесс разрушения ароматических структур имеет несколько стадий, приводящее в конечном итоге к разрыву ароматического кольца и деструкции лигнина. Первоначально происходит фрагмен- тация лигнина, а затем под действием нуклеофильного реагента $\mathrm{HO}_{2}^{-}$идет дополнительная деструкция лигнина и его производных. Причем обработка раствором пероксида водорода в щелочной среде приводит к большему разрушению ароматического кольца, чем в кислой (кривая 4).

Таким образом, на основании ИК-спектрофотометрических исследований можно сделать вывод, что наиболее благоприятные условия для полного удаления лигнинсодержащих примесей при обработке льняного волокна достигаются в щелочно - перекисном растворе.

Интересно сопоставить результаты спектрофометрических исследований с данными, характеризующими процесс делигнификации льноволокон при щелочных, щелочно-окислительных и щелочно-восстановительных обработках.

На рис. 3 показана кинетика растворения лигнина льноволокна под действием щелочной, щелочно-восстановительной (сульфитной) и щелочно-перекисной обработки.

Как следует из рисунка, введение сульфита натрия ускоряет процесс делигнификации льноволокна, а предварительная обработка перекисью водорода в щелочной среде способствует еще большему удалению лигнинсодержащих примесей, чем щелочная или щелочно-восстановительная. Так, при щелочно-окислительной варке остаточное содержание лигнина в 1,4 раза меньше, чем при щелочной варке, и в 1,12 раз, чем при щелочно-восстановительной, что подтверждает выводы о преимущественном окислительном распаде лигнина и возможном протекании конденсационных процессов в других условиях.

Ниже в таблице 2 приведены функциональные показатели льноволокна после проведения полно-

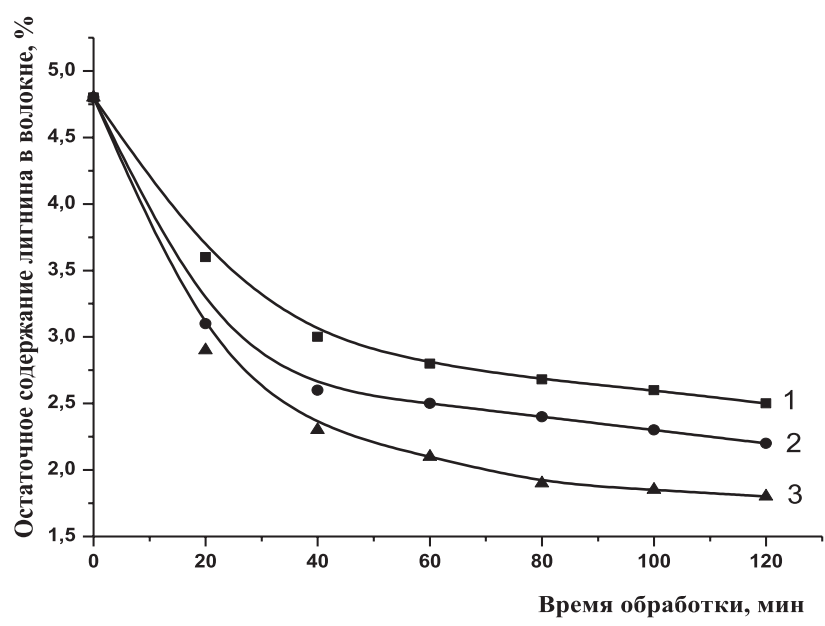

Рис. 3. Кинетика растворения лигнина при щелочной (1), щелочно-восстановительной (2) и щелочно-перекисной (3) обработке льноволокна 
Функциональные показатели льноволокна после проведения полного цикла химической модификации

\begin{tabular}{lcc}
\multicolumn{1}{c}{ Наименование показателя } & В суровом волокне & $\begin{array}{c}\text { В химически } \\
\text { модифицированном }\end{array}$ \\
\hline Содержание лигнина, \% & 4,8 & 1,5 \\
Содержание пектиновых веществ, \% & 4,4 & 0,2 \\
Содержание гемицеллюлоз, \% & 10,2 & 2,8 \\
Содержание жировых и воскообразных веществ, \%, & 2,6 & 0,35 \\
Капиллярность, мм, & - & 85 \\
Степень белизны, \% & - & 72 \\
\hline
\end{tabular}

го цикла химической модификации. Данные таблицы доказывают, что разработанная технология позволяет выпускать льноволокно и изготавливать из него льновату, соответствующую требованиям ГОСТ 5556-81 и ТУ 9393-001-047408402005 на вату медицинскую гигроскопическую хирургическую.

Таким образом, спектрофотометрическими исследованиями состояния нерастворившейся части лигнина выявлена значительная деструкция лигнинного компонента пероксидом водорода в щелочной и кислой средах. Сделан вывод, что увеличение содержания ОН-групп, включенных в водородные связи, и высокое остаточное содержание лигнинсодержащих примесей в льняном волокне после щелочной обработки обусловлено конденсацией низкомолекулярных продуктов, образующихся в щелочно-восстановительной системе.

\section{Выводы}

1. Изучение растворимости лигнина Класона, видоизмененного в процессе предшествующих гидролитических или окислительных воздействий, показало, что степень растворения лигнина в щелочной среде происходит в 2-3 раза выше, чем в кислой.

2. Методом ИК-спектроскопии изучено состояние лигнина Класона, видоизмененного обработкой щелочным, пероксидными растворами и последующей окислительной варкой. Анализ положения и интенсивности характеристических полос в полученных спектральных кривых показал, что их максимальные изменения по сравнению с исходными происходят после активации лигнина пероксидом водорода в щелочной и кислой средах. Менее значительный уровень изменений состояния лигнина в щелочной среде и увеличение содержания ОН-групп, включенных в межмолеку- лярные водородные связи, по-видимому, обусловлены конденсацией образующихся низкомолекулярных продуктов.

Исследования выполнены в рамках Государственного задания Института химии растворов им. Г.А. Крестова РАН (проект №01201260484) с использованием приборной базы ЦКП «Верхневолэский региональный изентр физико-химических исследований».

\section{Лumepamypa}

1. Демин В.А., Шерешовеи В.В., Монаков Ю.Б. Успехи химии. 1999. Т. 68 (11). С. 1029-1049.

2. Бытенский В.Я., Кузнецова Е.П. Производство эфиров целлюлозы. /Под ред. Н.И. Кленковой. Л.: Химия, 1974. с. 11.

3. Галашина В.Н., Морыганов А.П., Данилов А.Р. Текстильная промышленность. Научный альманах. 2007. № 4. С. 14-17.

4. Иванов А.Н. Изв. ВУЗов. Технология текст. пром-ти. 1982. № 1. С. 23-25.

5. Гелес И. С. Древесное сырье - стратегическая основа и резерв цивилизации. Петрозаводск: Карельский научный центр РАН, 2007. 499 с.

6. Карклинь В.Б. Химия древесины. 1981. №4. С. 38-44.

7. Хергерт Г.Л. ИК-спектры лигнина // Лигнины / Под ред. К.В. Сарканена и К.Х. Людвига. М., 1975. 632 c.

8. Азаров В.И., Буров А.В., Оболенская А.В. Химия древесины и синтетических полимеров. С.-Пб. 1999. $628 \mathrm{c}$.

9. Оболенская А.В. Химия лигнина. С.-Пб.: ЛТА, 1993. $80 \mathrm{c}$.

10. Фенгел Д. Древесина: химия, ультраструктура, реакции: пер. с англ. /Под ред. Д. Фенгел, Г.М. Вегенер. М.: Лесная пром-ть, 1988. 512 с.

11. Базарнова Н.Г., Карпова Е.В., Катраков И.Б. Методы исследования древесина и ее производных. Барнаул: изд-во Алт. ун-та, 2002. 160 с. 
12. Беллами Л. Инфракрасные спектры молекул: пер. с англ. В.М. Акимова, Ю.А. Пентина, Э.Г. Тетерина. /Под ред. Д.Н. Шигерина. М.: Изд-во иностр. литpa, 1957. $444 \mathrm{c}$.

13. Сильверстейн Р., Басслер Г., Морил Т. Спектроскопическая идентификация органических соединений: пер. с англ. М., 1977. 590 с.

14. Карклинь В.Б. Химия древесины. 1981. №4. С. 4549.
15. Султанов В. С. Химия древесины. 1985. № 1. С. 33-44.

16. Надеин А.Ф., Прокиин Г.Ф., Богомолов Б.Д. Химия древесины. 1986. №2. С. 63-67.

17. Гермер Э.И., Шагаев О.В. Химия древесины. 1984. № 1. С. 52-54.

18. Faix O., Schweers $W$. Vergleichende Untersuchungen an Polymermodellen des Lignins verschiedenen Zusammensetzungen. 3. Mitt. IR-spektroskopische Untersuchungen. Holzforschung.1974. Bd. 28. H. 2. S. 50-54. 